\title{
Effect of Peucedanum japonicum Thunb on the Expression of Obesity-Related Genes in Mice on a High-Fat Diet
}

\author{
Natthanan Nukitrangsan ${ }^{1,2}$, Takafumi Okabe ${ }^{2}$, Takayoshi Toda ${ }^{3}$, Masashi Inafuku², \\ Hironori Iwasaki ${ }^{2}$, Teruyoshi Yanagita ${ }^{4}$ and Hirosuke Oku ${ }^{2 *}$ \\ ${ }^{1}$ United Graduate School of Agricultural Sciences, Kagoshima University (1-21-24 Korimoto, Kagoshima 890-0065, JAPAN) \\ ${ }^{2}$ Center of Molecular Biosciences, Tropical Biosphere Research Center, University of the Ryukyus (1 Senbaru, Nishihara, Okinawa 903-0213, \\ JAPAN) \\ ${ }^{3}$ Department of Clinical Labolatory Medicine, School of Medicine, University of the Ryukyu Hospital (207 Uehara, Nishihara, Okinawa 903-0215, \\ JAPAN) \\ ${ }^{4}$ Laboratory of Nutrition Biochemistry, Department of Applied Biochemistry and Food Science, Saga University )1-Honjo, Saga 840-8502, \\ JAPAN)
}

\begin{abstract}
The present study describes the effect of Peucedanum japonicum Thunb (PJT) intake on the expression of obesity-related genes in mice fed a high-fat diet. To explore the mechanism underlying the effect of PJT, This study focused on the expression of genes, especially those related to obesity and metabolism syndrome, in the liver and adipose tissues. In agreement with our previous observations, intake of $10 \%$ PJT for 4 weeks significantly reduced serum triglyceride (TG), leptin, abdominal fat, and adipocyte size. PJT also significantly increased fecal excretion of TG, decreased that of bile acid, and tended to increase the fecal excretion of total cholesterol. Microarray analysis was used to monitor changes in 324 metabolic syndrome-related genes in the liver. Statistically significant upregulation of PPP1R10, RORC, and $P B E F 1$ genes and downregulation of DUSP1, INSIG2, and SERPINA12 genes were noted and confirmed by real-time RT-PCR. These changes were indicative of increased fatty acid oxidation in the maintenance of lipid homeostasis and insulin sensitivity in the livers of PJT-fed mice. PJT increased the expression of $P P A R \gamma, F X R \alpha, D G A T 1$, and $A T G L$ genes, suggesting an enhancement of adipocyte differentiation and normalization of functionality of adipose tissue.
\end{abstract}

Key words: metabolic syndrome, obesity, gene expression, Peucedanum japonicum Thunb

\section{INTRODUCTION}

In recent years, obesity has become one of the most prevalent health problem among developed countries, including Japan ${ }^{1)}$, and has been considered to be due to a high-fat diet and sedentary lifestyle ${ }^{2)}$. Obesity is not only an economic burden but also a risk factor for a variety of metabolic diseases, such as atherosclerosis, dyslipidemia, elevated blood pressure, and insulin resistance ${ }^{3-5}$. Therefore, it is very important to establish strategies for the prevention of obesity.

Peucedanum japonicum Thunb(PJT), a medicinal plant belonging to the family of Umbelliferae, grows on the cliffs of Okinawa Island, Japan. PJT leaves are traditionally consumed on Okinawa Island as a medicinal herb for the treatment of cough. The roots of this plant have been used as a folk medicine for cold and neuralgic diseases in Taiwan $^{6)}$. There have been several reports on the biological activity of $\mathrm{PJT}^{7-10)}$, which indicate the high potential of this plant in the development of natural agents for treatment of prevailing health problems. Our previous study reported for the first time that PJT inhibited high-fat-induced obesity in mice and resulted in a decrease in body weight of the mice ${ }^{11)}$. This anti-obesity activity of PJT appeared to be associated with decreased fat absorption, although the extent to which this mechanism is involved in the overall lipid-lowering activity of PJT is unknown. These findings also indicated an in vivo metabolic shift to inhibit obesity, and hence, more studies were required to explore the antiobesity mechanism of PJT.

In this study, we investigated the effect of PJT on the

\footnotetext{
*Correspondence to: Hirosuke Oku, Division of Molecular Biotechnology, Center of Molecular Bioscience, Tropical Biosphere Research Center, University of the Ryukyus, 1-Senbaru, Nishihara, Okinawa 903-0213, JAPAN

E-mail: okuhiros@comb.u-ryukyu.ac.jp

Accepted May 25, 2011 (received for review April 28, 2011)

Journal of Oleo Science ISSN 1345-8957 print / ISSN 1347-3352 online

http://www.jstage.jst.go.jp/browse/jos/ http://mc.manusriptcentral.com/jjocs
} 
expression of genes in liver and adipose tissues, which play a pivotal role in lipid metabolism. We focused on the expression of genes associated with the onset of obesity, and discussed the probable anti-obesity mechanism of PJT.

\section{EXPERIMENTAL PROCEDURES}

\subsection{Materials}

PJT used in this study was harvested from Yonaguni island of Okinawa, Japan. PJT leaves and stems were freeze-dried and ground by Yonagunijima Yakusoen Co. (Okinawa, Japan). The dried powder of PJT was analyzed by the Japan food Research Laboratories (Tokyo, Japan), and its nutrient composition was found to be as follows: carbohydrate, $46.7 \%$; fiber, $31.6 \%$; mineral, $9.8 \%$; protein, $7.6 \%$; and fat, $4.4 \%(\mathrm{w} / \mathrm{w})$. Casein, $\beta$-corn starch, cellulose, and mineral and vitamin mixes for AIN-76 rodent diets were purchased from Oriental Yeast Co., Ltd. (Tokyo, Japan). DL-methionine and choline bitartrate were purchased from Wako Pure Chemical Industries, Ltd. (Osaka, Japan).

\subsection{Animals and diets}

Three-week-old male C57BL/6 mice were purchased from Japan SLC, Inc. (Shizuoka, Japan). The animals were housed in a temperature-, humidity-, and light-controlled room (12-h light/dark cycle) and were allowed free access to water. The mice were maintained on commercial chow for 7 days to allow acclimatization, and were then fed $0 \%$ and 10\% PJT diets (AIN76 diet containing 15\% corn oil) for another 4 weeks. The composition of the experimental diets was as follows: carbohydrate, $53.0 \%$; protein, $20.0 \%$; fat; $15.0 \%$; fiber, $7.0 \%$; AIN-76 mineral mix, 3.5\%; AIN-76 vitamin mix, $1.0 \%$; DL-methionine, $0.3 \%$; choline bitartrate, $0.2 \%$; dried PJT powder, $0 \%$ or $10 \%(\mathrm{w} / \mathrm{w})$; and energy, $427.0 \mathrm{kcal} / 100 \mathrm{~g}$. In the dietary group with PJT powder, the additional protein, carbohydrate, fiber, and fat derived from PJT were compensated for by decreasing the corresponding nutrients: casein, sucrose, $\beta$-corn starch, cellulose, and corn oil. All animals were pair-fed on the diets and allowed free access to water. Mice were sacrificed after $6 \mathrm{~h}$ of fasting. The serum, liver tissue, and white adipose tissue (WAT) samples were collected, and stored at $-80^{\circ} \mathrm{C}$. Weights of liver tissue and WAT were measured immediately after collection.

\subsection{Lipid concentrations and biochemical parameters in the serum and liver}

Serum levels of total cholesterol (TC), triglyceride(TG), and glucose were determined using a commercial enzymatic kit (Wako Pure Chemical Industries, Ltd., Osaka, Japan). Serum leptin, adiponectin, and insulin levels were measured using ELISA kits (leptin and insulin: Morinaga Insti- tute of Biological Science, Inc., Yokohama, Japan; adiponectin: Otsuka Pharmaceutical Co., Ltd., Tokyo, Japan). Total lipids were extracted from liver tissues by a previously described method ${ }^{12)}$. Liver levels of TC and TG were determined by the Shoenheimer-Sperry method ${ }^{13)}$ and Fletcher's method $^{14)}$, respectively.

\subsection{Lipid concentration in feces}

During the last 3 days of the feeding period, fecal samples were collected and dried. The TC and TG in the feces were extracted by a previously described method ${ }^{12)}$, and their levels were determined using commercial enzymatic assay kits (Wako Pure Chemical, Osaka, Japan), as described previously ${ }^{15)}$. Total bile acids were extracted from the feces with $100 \%$ ethanol, and measured using the Total Bile Acid Test Wako kit(Wako Pure Chemical, Osaka, Japan).

\subsection{Adipocyte size}

The epididymal adipose tissue was fixed in 10\% buffered formalin, embedded in paraffin, and stained with hematoxylin and eosin for microscopic measurement of cell sizes, as described elsewhere ${ }^{16)}$. The stained sections were viewed at $20 \times$ magnification, and photographed with a digital camera (Olympus BX41, NY, USA); the images were converted into a binary format by using Adobe Photoshop 5.0.1 software (Adobe Systems, CA, USA), and incorporated into Scion Image for measurement of the cross-sectional area. The total cross-sectional areas of at least 200 adipocytes were manually measured for 4 microscopic fields, and used for calculation of the average cell surface area $\left(\mu \mathrm{m}^{2}\right)$.

\subsection{Isolation of total RNA}

Total RNA was extracted from $30 \mathrm{mg}$ of liver tissue by using the Illustra RNA spin mini RNA isolation kit (GE Healthcare, NJ, USA), and also from $30 \mathrm{mg}$ of epididymal adipose tissue by using the RNeasy lipid tissue mini kit (Qiagen, CA, USA). Purity of RNA was checked using agarose gel electrophoresis, and quantified by a UV spectrophotometer. Five micrograms of total RNA was reverse transcribed to produce cDNA by an oligo (dt) method using the PrimeScript ${ }^{\mathrm{TM}} 1^{\text {st }}$ strand cDNA synthesis kit (Takara BIO Inc., Shiga, Japan). cDNA samples were stored at $-80^{\circ} \mathrm{C}$ in aliquots of $50 \mu \mathrm{L}$.

\subsection{Microarray analysis}

mRNA expression analyses of 333 genes (including 324 lifestyle disease-related genes as summarized in Table 1 and 9 housekeeping genes)were performed using a Gene SQUARE DNA array (Kurabo Industries Ltd., Osaka, Japan). Briefly, fluorescence- labeled cDNA synthesized from $10 \mu \mathrm{g}$ of total RNA was mixed with standard saline citrate and sodium dodecyl sulfate in a volume of $20 \mu \mathrm{L}$. 
Table 1 Microarray analysis of gene expression in the liver.

\begin{tabular}{|c|c|c|}
\hline Gene group & $\begin{array}{c}\text { Number of genes } \\
\text { studied }\end{array}$ & $\begin{array}{l}\text { Modulated gene } \\
\text { name }(p<0.05)^{\mathrm{a}}\end{array}$ \\
\hline Adipogenesis & 10 & RORC $\uparrow$ \\
\hline Adipocyte related gene & 18 & \\
\hline Regulators and adipocyte differentiation & 44 & SERPINA12 $\downarrow$ \\
\hline Lipid metabolism & 47 & CYP7A1 $\uparrow$ \\
\hline Lipid metabolism related gene & 5 & \\
\hline Glucose and glycogen metabolism & 19 & \\
\hline Insulin signal & 54 & $\begin{array}{l}\text { PBEF1 } \\
\text { PPP1R1 } \\
\text { INSIG2 }\end{array}$ \\
\hline MAPK signal & 20 & \\
\hline AMPK signal & 4 & \\
\hline PPAR & 18 & \\
\hline Wnt signal & 15 & \\
\hline Beta cell related genes & 5 & \\
\hline Diabetes & 11 & \\
\hline Extra cellular matrix & 4 & \\
\hline Exocytosis & 10 & \\
\hline Immune response & 11 & \\
\hline Transporters & 25 & \\
\hline Others & 4 & DUSP1 $\downarrow$ \\
\hline
\end{tabular}

Eight microliters of this hybridization mix was applied to Gene SQUARE DNA array, and hybridized at $65^{\circ} \mathrm{C}$ for $15 \mathrm{~h}$. The fluorescence profile was analyzed by a microarray scanner (GenePix 4000B with GenePix Pro 6.0.1.27; Filgen, CA, USA). The expression level of an individual gene was presented as an arbitrary unit, normalized to the housekeeping gene, glyceraldehyde-3-phosphate dehydrogenase $(G A P D H)$ mRNA.

\subsection{Quantitative real-time RT-PCR}

Quantitative real-time RT-PCR was performed on an Icycler(Bio-Red Laboratory, Tokyo, Japan) using SYBR Green I(Takara BIO Inc., Shiga, Japan) and Takara Taq ${ }^{\text {TM }}$ Hot Start version(Takara BIO Inc., Shiga, Japan), according to the manufacturer's instructions. The primer sequences are listed in Table 2. Amplification of the target cDNA was checked by agarose gel electrophoresis and by identification of its DNA sequence, as described previous$\mathrm{ly}^{17)}$. A standard curve for each gene was constructed by performing PCR with serially diluted known concentrations of the template, and used for the estimation of target mRNA, as described elsewhere ${ }^{18)}$. Each sample was assayed in duplicate and normalized to GAPDH expression in liver tissues and $\beta$-actin expression in adipose tissues.

\subsection{Statistical analysis}

Statistical significance of the mean values of the 2 groups was evaluated using Student's $t$ test and the SAS statistical software program (SAS Institute, Tokyo, Japan).

\section{RESULTS}

\subsection{Growth parameters and weights of liver and adipose tissues}

Table 3 summarizes the growth parameters as well as the weights of the liver and adipose tissue samples. The mean final body weight of the 10\% PJT diet group was significantly lower than that of the $0 \%$ PJT diet group. No significant differences were noted for food and energy intake values. The relative mean liver weight of the $10 \%$ PJT diet group was significantly higher than that of the 0\% PJT diet group.

In the case of WAT, a significant decrease in the mean 
Table 2 Primers sequences used for quantitative real-time RT-PCR.

\begin{tabular}{|c|c|c|c|c|}
\hline Genes & Description & Primer sequence & Product & Accession no. \\
\hline \multirow[t]{2}{*}{ CYP7A1 } & cholesterol 7- $\alpha$-hydroxylase & 5'-AGC AAC TAA ACA ACC TGC CAG TAC TA-3' (forward primer,F) & 82 & NM_007824 \\
\hline & & 5'-GTC CGG ATA TTC AAG GAT GCA-3' (reverse primer, R) & & \\
\hline \multirow{2}{*}{$\begin{array}{l}\text { PBEF1 } \\
\text { (visfatin) }\end{array}$} & pre-b-cell colony-enhancing factor 1 & 5'-GCT GAT CCC AAC AAA AGG TC-3' (forward primer, F) & 204 & NM_021524 \\
\hline & & 5'-CTG CTC GAT GTT CAG CTG TG-3' (reverse primer, R) & & \\
\hline \multirow[t]{2}{*}{ PPP1R10 } & protein phosphatase 1 , regulatory subunit 10 & 5'-TGA TGG AGG CCA CAG TCA TG-3' (forward primer, F) & 104 & NM_001163818 \\
\hline & & 5'-GGT AGA AGG CAC AGT TGT TC-3' (reverse primer, R) & & \\
\hline \multirow[t]{2}{*}{ RORC } & RAR-related orphan receptor $\gamma$ & 5'-CAA TTT GGA ACT GGC TTT CC-3' (forward primer, F) & 189 & NM_011281 \\
\hline & & 5'- CTG AAG AGT TCC TTA TAG AG -3' (reverse primer, R) & & \\
\hline \multirow[t]{2}{*}{ DUSP1 } & dual specificity phosphatase 1 & 5'-TGA CAT GCG CGT ATG AGA G-3' (forward primer, F) & 182 & NM_013642 \\
\hline & & 5'- CTG GCT TTG TCT GTC AGT GC-3' (reverse primer, R) & & \\
\hline \multirow[t]{2}{*}{ INSIG2 } & insulin induced gene 2 & 5'-CAG AGG TGG TTA TCA ACA TC-3' (forward primer, F) & 209 & NM_133748 \\
\hline & & 5'-CTG TGA GCT TCA GTA GCC A -3' (reverse primer, R) & & \\
\hline \multirow{2}{*}{$\begin{array}{c}\text { SERPINA12 } \\
\text { (Vaspin) }\end{array}$} & serine (or cysteine) peptidase inhibitor, clade A & 5'-GCT CCG CAT CTC GTC TAC TT -3' (forward primer, F) & 151 & NM_026535 \\
\hline & (alpha-1 antiproteinase, antitrypsin), member 12 & 5'-CTT CCA TGC CTT TCT CAT CC -3' (reverse primer, R) & & \\
\hline \multirow[t]{2}{*}{ PPAR $\alpha$} & peroxisome proliferator activated receptor $\alpha$ & 5'-CCT CAG GGT ACC ACT ACG GAG T-3 (forward primer, F) & 69 & NM_011144 \\
\hline & & 5'-GCC GAA TAG TTC GCC GAA-3 (reverse primer, R) & & \\
\hline \multirow[t]{2}{*}{$\operatorname{PPAR} \gamma$} & peroxisome proliferator activated receptor $\gamma$ & 5'-AGG CCG AGA AGG AGA AGC TGT TG-3' (forward primer, F) & 276 & NM_011146 \\
\hline & & 5'-TGG CCA CCT CTT TGC TGT GCT C-3' (reverse primer, R) & & \\
\hline \multirow[t]{2}{*}{ FAS } & fatty acid synthase & 5'-TGC TCC CAG CTG CAG GC-3' (forward primer, F) & 91 & AF_127033 \\
\hline & & 5'-GCC CGG TAG CTC TGG GTG TA-3' (reverse primer, R) & & \\
\hline \multirow[t]{2}{*}{ FXR $\alpha$} & farnesoid $\mathrm{X}$ receptor $\alpha$ & 5'-TGG GCT CCG AAT CCT CTT AGA-3' (forward primer, F) & 72 & NM_001163504 \\
\hline & & 5'-TGG TCC TCA AAT AAG ATC CTT GG-3' (reverse primer, R) & & \\
\hline \multirow[t]{2}{*}{ SREBP-1 } & sterol regulatory element-binding protein-1 & 5'-GCG CCA TGG ACG AGC TG-3' (forward primer, F) & 205 & NM_011480 \\
\hline & & 5'-TTG GCA CCT GGG CTG CT-3' (reverse primer, R) & & \\
\hline \multirow[t]{2}{*}{$\mathrm{C} / \mathrm{EBP} \alpha$} & CCAAT/enhancer binding protein $\alpha$ & 5'-TGG ACA AGA ACA GCA ACG AGT AC-3' (forward primer, F) & 257 & NM_007678 \\
\hline & & 5'-GCA GTT GCC CAT GGC CTT GAC-3' (reverse primer, R) & & \\
\hline \multirow[t]{2}{*}{ PEG1/MEST } & paternally expressed gene $1(\mathrm{Peg} 1) /$ mesoderm specific & 5'-GTT TTT CAC CTA CAA AGG CCT ACG-3' (forward primer, F) & 52 & NM_008590 \\
\hline & transcript (Mest) & 5'-CAC ACC GAC AGA ATC TTG GTA GAA-3' (reverse primer, R) & & \\
\hline \multirow[t]{2}{*}{ DGAT1 } & diacylglycerol acyltransferase 1 & 5'-TCC GCC TCT GGG CAT TC-3' (forward primer, F) & 65 & NM_010046 \\
\hline & & 5'-GAA TCG GCC CAC AAT CCA-3' (reverse primer, R) & & \\
\hline \multirow[t]{2}{*}{ ATGL } & adipose triglyceride lipase & 5'-AGG ACA GCT CCA CCA ACA TC-3' (forward primer, F) & 165 & AY894805 \\
\hline & & 5'-TGG TTC AGT AGG CCA TTC CT-3' (reverse primer, R) & & \\
\hline \multirow[t]{2}{*}{ LPL } & lipoprotein lipase & 5'-AGG GCT CTG CCT GAG TTG TA-3' (forward primer, F) & 199 & NM_008509 \\
\hline & & 5'-AGA AAT CTC GAA GGC CTG GT-3' (reverse primer, R) & & \\
\hline \multirow[t]{2}{*}{ UCP2 } & uncoupling protein-2 & 5'-CAG GTC ACT GTG CCC TTA CCA T-3' (forward primer, F) & 101 & NM_011671 \\
\hline & & 5'-CAC TAC GTT CCA GGA TCC CAA G-3' (reverse primer, R) & & \\
\hline \multirow[t]{2}{*}{ GAPDH } & glyceraldehyde-3-phosphate dehydrogenase & 5'-ACC CAG AAG ACT GTG GAT GG-3' (forward primer, F) & 172 & NM_008084 \\
\hline & & 5'-ACA CAT TGG GGG TAG GAA CA-3' (reverse primer, R) & & \\
\hline \multirow[t]{2}{*}{ ACTB } & actin, beta, cytoplasmic & 5'-CAG AAG GAG ATT ACT GCT CTG GCT-3' (forward primer, F) & 93 & NM_007393 \\
\hline & & 5'-GGA GCC ACC GAT CCA CAC A-3' (reverse primer, R) & & \\
\hline
\end{tabular}

weight of abdominal fat, including epididymal and perirenal fat, was noted for the 10\% PJT diet group. The subcutaneous fat weight tended to decrease in the 10\% PJT diet group. These results largely agree with our previous observations with PJT-fed mice ${ }^{11)}$.

\subsection{Adipocyte size}

The mean cell size of the epididymal adipocytes for the mice fed with $10 \%$ PJT diet was significantly smaller than that for the $0 \%$ PJT diet group, as exemplified in Fig. 1-A. The average adipocyte sizes were $4259(227) \mu m^{2}$ (mean (SD)) and $2694(139) \mu \mathrm{m}^{2}$ for the $0 \%$ and $10 \%$ PJT diet group, respectively (Fig. 1-B).

\subsection{Lipid metabolism-related parameters}

Table 4 shows the serum levels of TC, TG, glucose, 
Table 3 Effect of Peucedanum japonicum Thunb (PJT) on growth parameters, and weight of liver and adipose tissues in mice.

\begin{tabular}{lcc}
\hline \multirow{2}{*}{ Parameters } & \multicolumn{2}{c}{ Diet group $^{\mathrm{a}}$} \\
& $0 \%$ & $10 \%$ \\
\hline Food intake (g/day) & $2.9 \pm 0.0$ & $2.9 \pm 0.0$ \\
Energy intake (kcal/day) & $12.49 \pm 0.06$ & $12.44 \pm 0.10$ \\
Initial body weight (g) & $13.5 \pm 0.4$ & $13.5 \pm 0.3$ \\
Final body weight $(\mathrm{g})$ & $22.4 \pm 0.4$ & $18.9 \pm 0.4^{* *}$ \\
Liver weight $(\mathrm{g} / 100 \mathrm{~g}$ body weight) & $4.2 \pm 0.1$ & $4.6 \pm 0.1^{*}$ \\
\hline White adipose tissue (g/100 g body weight) & $7.39 \pm 0.68$ & $5.78 \pm 0.51$ \\
Abdominal fat & $5.50 \pm 0.24$ & $3.87 \pm 0.34^{* *}$ \\
$\quad$ Epididymal fat & $2.76 \pm 0.11$ & $1.82 \pm 0.13^{* *}$ \\
$\quad$ Perirenal fat & $1.05 \pm 0.07$ & $0.55 \pm 0.10^{* *}$ \\
$\quad$ Omental fat & $1.70 \pm 0.17$ & $1.49 \pm 0.13$ \\
Subcutanous fat & $2.35 \pm 0.24$ & $1.90 \pm 0.17$ \\
Brown adipose tissue (g/100 g body weight) & $0.67 \pm 0.06$ & $0.42 \pm 0.04^{* *}$ \\
\hline${ }^{a}:$ C57BL/6 mice were fed modified-AIN76 diet containing $15 \%$ corn oil with $0 \%$ or \\
$10 \%$ PJT for 4 weeks. Values are mean \pm SE of six mice. Asterisk shows significant \\
difference from 0\% PJT diet group by Student's t test $(*: p<0.05, * *: p<0.01)$.
\end{tabular}

insulin, adiponectin, and leptin; levels of TC and TG in the liver; and fecal excretion of TC, TG, and bile acid. Mice that were fed 10\% PJT diet showed significantly lower serum TG and leptin levels than those fed 0\% PJT diet. Moreover, the $10 \%$ PJT diet tended to increase the serum adiponectin level $(p=0.155)$. No significant differences were noted in the serum levels of TC, glucose, and insulin between the 2 dietary groups.

The liver TG level of the 10\% PJT diet group was significantly lower than that of the $0 \%$ PJT diet group. As observed for the serum samples, PJT diet had no effect on the liver TC level.

PJT significantly increased the fecal excretion of TG, decreased that of bile acid, and tended to increase the fecal excretion of $\operatorname{TC}(p=0.08)$.

\subsection{Microarray analysis of gene expression in the liver}

Table 1 summarizes the PJT diet-induced modulation of gene expression in the liver; only the significantly modulated genes $(p<0.05)$ are listed in this Table. Seven of the analyzed 324 genes showed significant changes in response to PJT administration. PJT diet upregulated the gene expression of RORC, CYP7A1, PBEF1, and PPP1R10 by 1.5-2 fold, and downregulated SERPINA12 (vaspin), INSIG2, and DUSP 1 by $0.2-0.3$ fold. No significant changes were noted for other genes that are important in liver lipid metabolism, namely, PPAR $\alpha, F A S$, and SREBP-1 genes.
3.5 Analysis of gene expression in liver and adipose tissues by real-time RT-PCR

Analysis by real-time RT-PCR confirmed the increase in expression of $R O R C, P P P 1 R 10$, and PBEF1 in the liver due to the PJT diet, as shown in Fig. 2-A. Decreases in the expression of DUSP1, INSIG2, and SERPINA12 to variable extents were also noted (Fig. 2-B). There were increasing tendencies of FXR $\alpha$ and SREBP-1 expression in the livers of PJT-fed mice, and no difference was found in PPAR $\alpha$ and FAS expression (Fig. 2-C) .

Figure 3 shows the gene expression in adipose tissue. Genes that are important in lipid metabolism in lipid metabolism were selected for analyses, based on a review of literature. Compared to the 0\% PJT diet, the 10\% PJT diet significantly upregulated the gene expression of PPAR , $F X R \alpha, D G A T 1$, and $A T G L$, and downregulated the gene expression of $P E G 1 / M E S T$. No significant differences were noted for the expression levels of $P B E F 1, R O R C, C / E B P \alpha$, $S R E B P-1, L P L$, and $U C P 2$ in adipose tissue.

\section{DISCUSSION}

The present study confirmed the anti-obesity activity of PJT in mice. The observed influences of PJT on lipid parameters and body weight gain in the present study were in agreement with the observations in our previous study; PJT reduced serum TG, leptin, abdominal fat, and adipocyte size, with a concomitant decrease in body weight (Tables 3 and 4, Fig. 1). Furthermore, increased fecal TG 
A
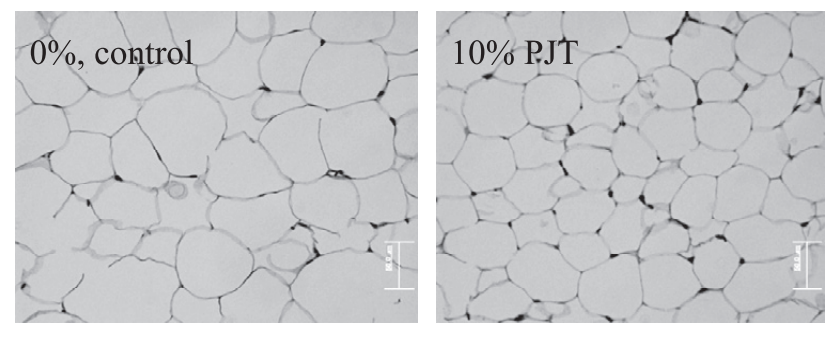

B

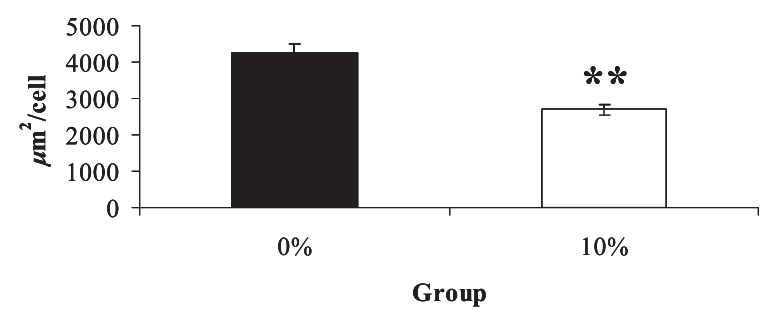

Fig. 1 Effect of Peucedanum japonicum Thunb (PJT) on adipocyte size.

Microscopic observation (A) and cell size of epididymal adipocytes (B) in mice fed with $(10 \%)$ or without $(0 \%)$ PJT. Values in B were the mean $\pm \mathrm{SE}$ of 6 mice. Asterisks denote a statistically significant difference from the $0 \%$ PJT diet group (Student's $t$ test; *: $p<0.05, * *$ : $p<0.01)$.

and TC excretion, and decreased bile acid excretion were noted in the PJT-fed mice.

It has been reported that supplementation with persimmon leaf powder decreased TC and TG levels in the plasma and liver, and increased daily fecal weight and fecal excretion of TC and TG in rats that were fed a high-fat diet ${ }^{19)}$. This study suggested that fiber might be responsible for an improvement of fat metabolism. However, the total fiber level of all experimental diets in our study was adjusted to the same level by using cellulose. It is, therefore, unlikely that the increased fecal lipid excretion in the PJT diet group is due to a difference in the fiber content of the diet. Instead, a dietary component, other than fiber, may be responsible for the decreased lipid absorption. Our preliminary results showed that PJT was rich in polyphenol, which inhibits lipase to reduce lipid absorption, as suggested for tea catechins ${ }^{20)}$. Furthermore, several lines of in vitro studies have demonstrated the occurrence of hypolipidemic compounds in PJT leaves ${ }^{9,10)}$. It is, therefore, likely that these active components may influence the lipid dynamics, in concert, to prevent the mice from developing obesity.
In order to gain insight into the mechanism of action of PJT, its effect on gene expression in liver and adipose tissues were studied. Of the upregulated genes in the liver, increases in $R O R C$ and $P B E F 1$ levels were prominent. The protein encoded by the $R O R C$ gene is a DNA-binding transcription factor and is a member of the NR1 subfamily of the nuclear hormone receptors. The specific functions of this protein are not fully understood. However, a study in mouse skeletal muscle cells suggested that RORC increased the expression of the retinoid-related orphan receptor alpha $(R O R \alpha)$ gene, and thereby modulated the expression of genes involved in the control of lipid homeostasis, such as fatty acid binding protein, fatty acid translocase, lipoprotein lipase, and uncoupling protein $3^{21}$. Furthermore, $R O R \alpha$ directly regulates the transcription of carnitine palmitoyltransferase $1^{22}$. Therefore, it is likely that PJT increased the $\beta$-oxidation of fatty acids via the elevation of the $R O R C$ level and subsequent activation of $R O R \alpha$. This explanation is in line with our previous results that demonstrated increased carnitine palmitoyltransferase activity in the livers of PJT-fed mice ${ }^{11)}$.

PBEF1 (visfatin) is an adipokine that is involved in glucose homeostasis through its glucose-lowering effect ${ }^{23}$. It was initially thought that visfatin had insulin-mimicking functions, stimulating glucose utilization in the peripheral tissues $^{23)}$. However, visfatin has now been identified as the extracellular form of the enzyme nicotineamide phosphoribosyltransferase (NAMPT), which is essential in the NAD biosynthesis pathway and critical for glucose-stimulated insulin secretion in $\beta$-cells. Furthermore, a recent study demonstrated that overexpression of visfatin altered whole body insulin sensitivity and lipid profile in rats ${ }^{24}$. Thus, the increased expression of visfatin in PJT-fed mice may represent their improved insulin sensitivity. The precise mechanism underlying the aforementioned beneficial activity of visfatin is not fully understood. More studies are needed to explore the physiological significance of increased visfatin gene expression in PJT-fed mice.

The PJT diet significantly lowered the expression of INSIG2 and DUSP1 genes in the liver. The decreased expression of INSIG2 gene may represent sensitized insulin signaling in PJT-fed mice, which could occur because the diet ensures the endoplasmic supply of SREBP-1 to the Golgi. In this sense, it is also notable that the reduced gene expression of DUSP1, which inactivates MAP kinase in insulin-mediated signaling, may contribute to the anti-obesity activity of PJT. Consistent with this scenario, downregulation of MAP kinase phosphatase-1 enhanced resistance to diet-induced obesity in mice ${ }^{25}$.

PJT upregulated the expression of PPAR,$F X R \alpha$, $D G A T 1$, and ATGL genes in adipose tissue (Fig. 3). Of these genes, the nuclear hormone receptors $(P P A R \gamma$ and $F X R \alpha)$ are important transcription factors involved in the regulation of essential metabolic functions, including 
Table 4 Effect of Peucedanum japonicum Thunb (PJT) on lipid metabolismrelated parameters in mice.

\begin{tabular}{|c|c|c|c|c|c|}
\hline \multirow{2}{*}{ Parameters } & \multicolumn{5}{|c|}{ Diet group $^{a}$} \\
\hline & & $0 \%$ & & & $10 \%$ \\
\hline \multicolumn{6}{|l|}{ Serum } \\
\hline Total cholesterol (mg/dL) & 137.3 & \pm & 3.2 & 165.4 & \pm 12.6 \\
\hline Triglyceride (mg/dL) & 55.7 & \pm & 5.3 & 35.0 & $\pm 5.8^{*}$ \\
\hline Adiponectin (ng/mL) & 2.37 & \pm & 0.08 & 2.53 & $3 \pm 0.07$ \\
\hline Leptin $(\mathrm{ng} / \mathrm{mL})$ & 7.52 & \pm & 0.53 & 3.55 & $5 \pm 0.92 *$ \\
\hline Glucose (mg/dL) & 68.4 & \pm & 16.3 & 61.3 & \pm 19.6 \\
\hline Insulin $(\mathrm{pg} / \mathrm{mL})$ & 197.0 & & 35.0 & 152.0 & \pm 48.0 \\
\hline \multicolumn{6}{|l|}{ Liver tissue } \\
\hline Total cholesterol (mg/g liver) & 3.83 & \pm & 0.20 & 3.88 & $8 \pm 0.21$ \\
\hline Triglyceride (mg/g liver) & 65.8 & \pm & 5.4 & 47.4 & $\pm 3.0^{* *}$ \\
\hline \multicolumn{6}{|l|}{ Fecal excretion } \\
\hline Total cholesterol (mg/day) & 3.33 & \pm & 0.20 & 4.24 & $4 \pm 0.21$ \\
\hline Triglyceride (mg/day) & 0.32 & \pm & 0.08 & 0.51 & $1 \pm 0.04 *$ \\
\hline Bile acid (mg/day) & 1.28 & \pm & 0.09 & 0.77 & $7 \pm 0.08 * *$ \\
\hline
\end{tabular}

glucose and lipid metabolism ${ }^{26)}$.

PPAR $\gamma$ gene is a master regulator of adipogenesis in adipose tissue. The physiological significance of the current findings is rather ambiguous and somewhat controversial. PPAR belongs to the nuclear receptor superfamily of ligand-activated transcription factors. The earliest events occurring in adipogenesis are a brief burst of mesenchymal precursor cells, followed by cell-cycle arrest and terminal differentiation ${ }^{27}$. PPAR $\gamma$ expression is induced at the stage of terminal differentiation in adipogenesis, and assists in the completion of the process involved in the production of mature adipocytes ${ }^{27)}$. Thus, the lipid-lowering activities of several natural compounds have been explained, in part, by the downregulation of the PPARy gene ${ }^{28)}$. In contrast to these observations, in this study, PJT increased the expression of the $P P A R \gamma$ gene without causing any detrimental obesity. Obesity is essentially due to over-nutrition or positive energy balance. The functionality of adipose tissue is associated with its ability to buffer the accumulation of the excess energy consumed in the diet, and to provide energy as free fatty acids when the energy expenditure exceeds intake. Therefore, the decreased adipose tissue weight in the PJT diet may simply be a consequence of reduced lipid levels available for adipogenesis.

It is noteworthy that the activation of the PPARr gene in adipose tissue prevents adipocyte hypertrophy and metabolic abnormalities during obesity ${ }^{29)}$. Adipose tissue regulates the metabolism of other fat cells or cells located in the brain, liver, muscle, or pancreas via the secretion of adipocytokines. Adipocyte enlargement is associated with disruption in the adipokine profile and dysfunction of fat cells ${ }^{30)}$. In this regard, increased differentiation by PPAR may result in the production of small adipocytes with normal functionality. Hypoxia in adipose tissue induced by adipocyte enlargement is an emerging physiological event that may initiate the inflammatory response of adipose tissue $^{31)}$. PJT may accelerate adipocyte differentiation to yield small adipocytes, which may offset the adverse effects of fat accumulation in adipose tissue. This explanation may be supported by the observation that the PJT diet decreased the adipocyte size (Fig. 1) and the expression of the PEG1/MEST gene (Fig. 3), an adipocyte size marker ${ }^{32)}$.

$F X R$ is a nuclear receptor and bile acid sensor expressed in the liver, intestine, adrenal gland, and adipose tissue ${ }^{33}$. It has been shown that activation of FXR in adipose tissue increased insulin sensitivity and led to phosphorylation of the insulin receptor substrate-1 (IRS-1) and Akt, resulting in increased expression of the glucose transporter type-4 (Glut-4), adiponectin, and fatty acid binding-protein ${ }^{34)}$. Therefore, as observed in the liver, PJT may enhance the insulin response of adipose tissue via $F X R$ activation.

In conclusion, a lipid-lowering mechanism for PJT is proposed as follows: PJT inhibits the absorption of TG and TC, which may be the first and most critical step of the lipidlowering activity of this medicinal food. The inhibition of lipid absorption may subsequently limit the excess energy 

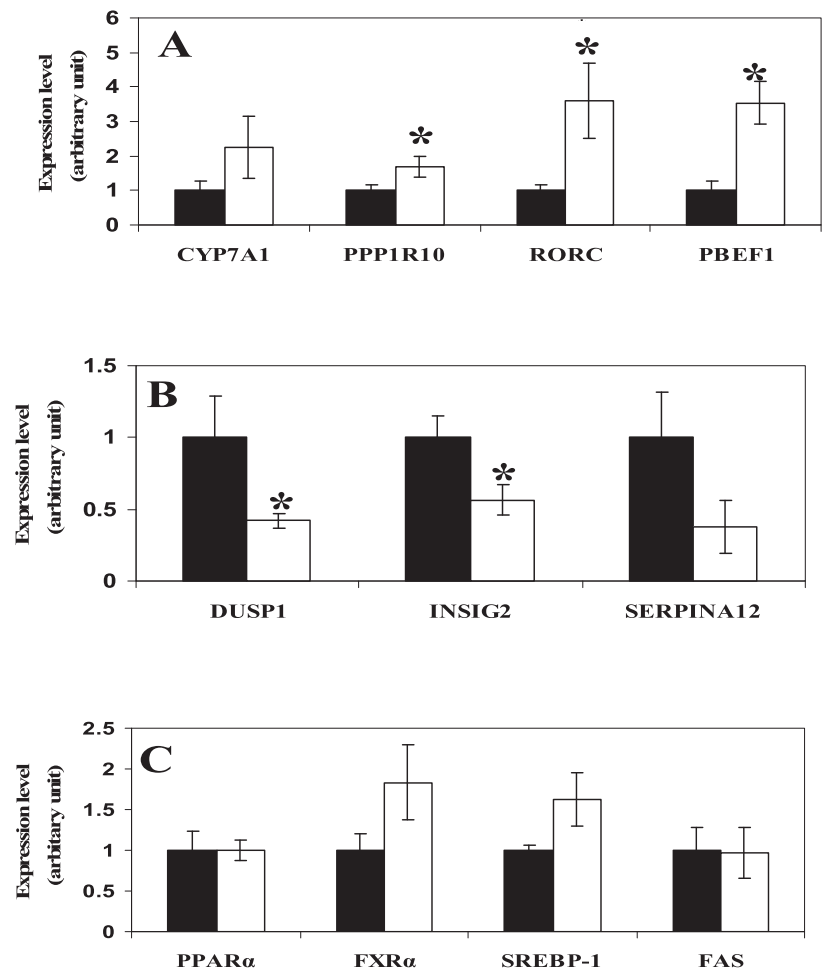

Fig. 2 Effect of Peucedanum japonicum Thunb (PJT) on gene expression in liver tissue determined by quantitative real-time RT-PCR.

A, genes upregulated in the foregoing microarray analysis; B, genes downregulated in the microarray analysis; $\mathrm{C}$, other well-documented and important genes in lipid metabolism. For descriptions of genes, see Table 2. Closed and open columns, respectively, show values for $0 \%$ and $10 \%$ PJT diet groups. Values are in arbitrary units, expressed as the mean \pm SE of 6 mice. Asterisk denotes a statistically significant difference from $0 \%$ PJT diet group (Student's $t$ test; *: $p<0.05)$.

required for fat storage in adipose tissue. Decreased bile acid excretion, caused by PJT, may increase the return flow of bile acid from the small intestine to the liver and affect lipid metabolism in the whole body, including liver and adipose tissues. In addition, PJT may enhance insulin sensitivity of both liver and adipose tissues via the normalization of the functionality of adipose tissue. Although no changes in serum glucose and insulin levels were noted in this study, the possibility of increased insulin sensitivity associated with PJT should be evaluated by glucose tolerance tests in future studies. In this context, future studies also should focus on the effects of PJT on the muscle tissue, which is important for the energy metabolism of the whole

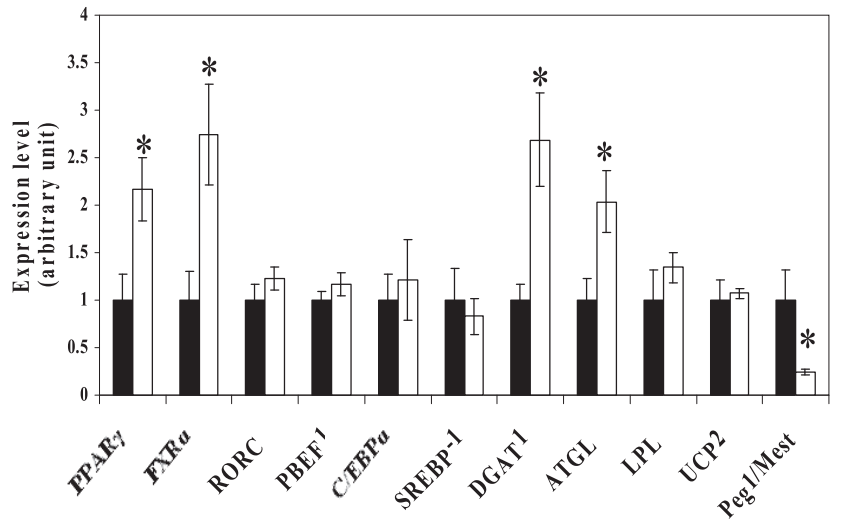

Fig. 3 Effect of Peucedanum japonicum Thunb (PJT) on gene expression in adipose tissues determined by quantitative real-time RT-PCR.

For descriptions of genes, see Table 2. Closed and open columns, respectively, show the value for $0 \%$ and $10 \%$ PJT diet groups. Values are arbitrary units, expressed as the mean \pm SE of 6 mice. Asterisk denotes a statistically significant difference from $0 \%$ PJT diet group (Student's $t$ test; *: $p<0.05$ )

body.

\section{References}

1) Nestel, P.; Lyu, R.; Low, L. P.; Sheu, W. H.; Nitiyanant, W.; Saito, I.; Tan, C. E. Metabolic syndrome: recent prevalence in East and Southeast Asian populations. Asia Pac J. Clin. Nutr. 16, 362-367 (2007).

2) Seidell, J. C. Dietary fat and obesity: an epidemiologic perspective. Am. J. Clin. Nutr. 67, 546-550 (1998).

3) McGill, H. C. Jr.; McMahan, C. A.; Herderick, E. E.; Zieske, A. W.; Malcom, G. T.; Tracy, R. E.; Strong, J. P. Obesity accelerates the progression of coronary atherosclerosis in young men. Circulation 105, 2712-2718(2002).

4) Howard, B. V.; Robbins, R. G. Obesity and dyslipidemia. Endocrinol. Matab. Clin. North Am. 32, 855-867 (2003).

5) Wallen, K. E.; Hotamisligil, G. S. Inflammation, stress, and diabetes. J. Clin. Invest. 115, 1111-1119(2005).

6) Chen, I. S.; Chang, C. T.; Sheen, W. S.; Teng, C. M.; Tsai, I. L.; Duh, C. Y.; Ko, F. N. Coumarins and antiplatelet aggregation constituents from Formosan Peucedanum japonicum. Phytochem. 41, 525-530 (1996).

7) Hisamoto, M.; Kikuzaki, H.; Ohigashi, H.; Nakatani, N. Antioxidant compounds from the leaves of Peucedanum japonicum Thunb. J. Agric. Food Chem. 51, 
5255-5261 (2003).

8) Hisamoto, M.; Kikuzaki, H.; Nakatani, N. Constituents of the leaves of Peucedanum japonicum Thunb and their biological activity. J. Agric. Food Chem. 52, 445-450 (2004).

9) Hsu, C. L.; Yen, G. C. Effects of flavonoids and phenolic acids on the inhibition of adipogenesis in 3T3-L1 adipocytes. J. Agric. Food Chem. 55, 8404-8410 (2007).

10) Li, B. H.; Ma, X. F.; Wu, X. D.; Tian, W. X. Inhibitory activity of chlorogenic acid on enzymes involved in the fatty acid synthesis in animals and bacteria. IUBMB. Life 58, 39-46 (2006).

11) Okabe, T.; Toda, T.; Nukitrangsan, N.; Inafuku, M.; Iwasaki, H.; Oku, H. Peucedanum japonicum Thunb inhibits high-fat diet induced obesity in mice. Phytother. Res. (2010) in press.

12) Folch, J.; Lees, M.; Sloane Stanley, G. H. A simple method for the isolation and purification of total lipids from animal tissues. J. Biol. Chem. 226, 497-509 (1957).

13) Sperry, W. M.; Webb, M. J. A revision of the Shoenheimer-Sperry method for cholesterol determination. J. Biol. Chem. 187, 97-106 (1950).

14) Fletcher, M. J. A colorimetric method for estimating serum triglycerides. Clin. Chim. Acta. 22, 393-397 (1986).

15) Attie, A. D.; Krauss, R. M.; Gray-Keller, M. P.; Brownlie, A.; Miyazaki, M.; Kastelein, J. J.; Lusis, A. J.; Stalenhoef, A. F.; Stoehrr, J. P.; Hayden, M. R.; Ntambi, J. M. Relationship between stearoyl-CoA desaturase activity and plasma triglycerides in human and mouse hypertriglyceridemia. J. Lipid Res. 43, 1899-1907 (2002).

16) Chen, H. C.; Farese, R. V. Determination of adipocyte size by computer image analysis. J. Lipid Res. 43, 986-989 (2002).

17) Matsumoto, K.; Yokoyama, S.; Gato, N. Bile acid-binding activity of young Persimmon(Diospyros kaki)fruit and its hypolipidemic effect in mice. Phytother. Res. 24, 205-210 (2009).

18) Wang, Y.; Zhu, W.; Levy, D. E. Nuclear and cytoplasmic mRNA quantification by SYBR green based real-time RT-PCR. Methods 39, 356-362(2006).

19) Lee, J. S.; Lee, M .K.; Ha, T. Y.; Bok, S. H.; Park, H. M.; Jeong, K. S.; Woo, M.-N.; Do, G. M.; Yeo, J.-Y.; Choi, M.-S. Supplementation of whole persimmon leaf improves lipid profiles and suppresses body weight gain in rats fed high-fat diet. Food Chem. Toxico. 44, 1875-1883 (2006)

20) Ikeda, I.; Tsuda, K.; Suzuki, M.; Kobayashi, T.; Unno, H.; Tomoyori, H.; Goto, H.; Kawata, Y.; Imaizumi, K.; Nozawa, A.; Kakuda, T. Tea catechins with a galloyl moiety suppress postprandial hypertriacylglycerolemia by de- laying lymphatic transport of dietary fat in rats. $J$ Nutr. 135, 155-159(2005).

21) Raichur, S.; Lau, P.; Staels, B.; Muscat, G. E. Retinoidrelated orphan receptor $\gamma$ regulates several genes that control metabolism in skeletal muscle cells: links to modulation of reaction oxygen species production. $J$. Mol. Endocrinol. 39, 29-44 (2007).

22) Lau, P.; Nixon, S. J.; Parton, R. G.; Muscat, G. E. RORalpha regulates the expression of gene involved in lipid homeostasis in skeletal muscle cells: caveolin-3 and CPT-1 are direct targets of ROR. J. Biol. Chem. 279, 36828-36840 (2004).

23) Guzik, T. J.; Mangalat, D.; Korbut, R. Adipocytokinesnovel link between inflammation and vascular function?. J. Physiol. Pharmacol. 57, 505-528(2006).

24) Sun, Q.; Li, L.; Li, R.; Yang, M.; Liu, H.; Nowicki, J.; Zong, H.; Xu, J.; Yang, G. Overexpression of visfatin/ $\mathrm{PBEF} /$ Nampt alters whole-body insulin sensitivity and lipid profile in rats. Ann. Med. 41, 311-320 (2009).

25) Wu, J.; Roth, R.; Anderson, E.; Hong, E.; Lee, M.; Choi, C.; Neufer, P.; Shulman, G.; Kim, J.; Bennett, A. Mice lacking MAP kinase phosphatase-1 have enhanced MAP kinase activity and resistance to diet-induced obesity. Cell Metab. 4, 61-73(2006).

26) Hansen, M. K.; Connolly, T. M. Nuclear receptors as drug targets in obesity, dyslipidemia and atherosclerosis. Curr. Opin. Invest. Drugs 9, 247-255(2008).

27) Lefterova, M. I.; Lazar, M. A. New developments in adipogenesis. Cell 20, 107-114(2009)

28) Rayalam, S.; Della-Fera, M. A.; Yang, J. Y.; Park, H. J.; Ambati, S.; Baile, C. A. Resveratrol potentiates genistein's antiadipogenic and proapoptotic effects in 3T3-L1 adipocytes. J. Nutr. 137, 2268-2273(2007).

29) Eugenia, M.; Vazquez-Vela, F.; Torres, N.; Tovar, A. R. White Adipose Tissue as Endocrine Organ and Its Role in Obesity. Arch. Med. Res. 39, 715-728(2008).

30) Molina, J. M.; Ciaraldi, T. P.; Brady, D.; Olefsky, J. M. Decreased activation rate of insulin-stimulated glucose transport in adipocytes from obese subjects. Diabetes 38, 991-995 (1989)

31) Hosogai, N.; Fukuhara, A.; Oshima, K.; Miyata, Y.; Tanaka, S.; Segawa, K.; Furukava, S.; Tochino, Y.; Komuro, R.; Matsuda, M.; Shimomura, I. Adipose tissue hypoxia in obesity and its impact on adipocytokine dysregulation. Diabetes 56, 901-911 (2007).

32) Takahashi, M.; Kamei, Y.; Ezaki, O. Mest/Peg1 imprinted gene enlarges adipocytes and is a marker of adipocyte size. Am. J. Physiol. Endocrinol. Metab. 288, 117-124 (2005).

33) Forman, B. M.; Goode, E.; Chen, J.; Oro, A. E.; Bradley, D. J.; Perlmann, T.; Noonan, D. J.; Burka, L. T.; McMorris, T.; Lamph, W. W.; Evans, R. M.; Weinberger, C. Identification of a nuclear receptor that is activated by farnesol metabolites. Cell 81, 687-693(1995). 
N. Nukitrangsan, T. Okabe, T. Toda et al.

34) Fiorucci, S.; Rizzo, G.; Donini, A.; Distrutti, E.; Santucci, L. Targeting farnesoid $\mathrm{X}$ receptor for liver and met- abolic disorders. TRENDS Mol. Med. Rev. 13, 298-309 (2007). 